\title{
Gonadal responses to food restriction in intact and pinealectomized male golden hamsters
}

\author{
Gail A. Eskes* \\ Department of Psychology, Berkeley, California 94720, U.S.A.
}

\begin{abstract}
Summary. Male golden hamsters underfed for $11-16$ weeks showed a $30 \%$ decrease in body weight accompanied by significant testicular regression. Pinealectomy did not prevent underfeeding-induced gonadal regression. Resumption of ad-libitum feeding restored body weights to near control levels and permitted testicular redevelopment in animals with previously regressed testes. These data indicate that chronic food restriction can affect the reproductive status of hamsters and that this effect does not depend on an intact pineal gland. Body weight changes may serve as a secondary proximate cue in addition to photoperiod for timing the hamster seasonal breeding cycle.
\end{abstract}

\section{Introduction}

The golden hamster (Mesocricetus auratus) is a seasonal breeder whose reproductive activity is affected by changes in photoperiod or ambient temperature. Hamsters maintained in photoperiods of less than $12.5 \mathrm{~h}$ of light daily (short days) or at an ambient temperature of $5-6^{\circ} \mathrm{C}$ for 5-10 weeks undergo testicular regression accompanied by a cessation of spermatogenesis (Hoffman, Hester \& Towns, 1965; Gaston \& Menaker, 1967; Frehn \& Liu, 1970; Reiter, 1981).

Nutrition is a third environmental factor that affects seasonal reproductive function in wild and domestic mammals, including sheep (Smith, 1965), montane, woodland and desert rodents (Pinter \& Negus, 1965; Watts, 1970; Kenagy \& Bartholomew, 1981), and lagomorphs (Kirkpatrick \& Kibbe, 1971). Nutritional status may also be an important proximate cue in the regulation of the hamster seasonal breeding cycle. Acute food deprivation has antigonadal effects in laboratory rats (see Mulinos \& Pomerantz, 1941; Howland, 1975) and hamsters (Howland \& Skinner, 1973a). Underfeeding can significantly reduce serum gonadotrophin and testosterone levels in male rats or hamsters; if prolonged, underfeeding can decrease testicular weight in rats (Grewal, Mickelson \& Hafs, 1971; Howland \& Skinner, 1973a; Campbell, Kurcz, Marshall \& Meites, 1977). Re-feeding reverses the effects of starvation on gonadotrophin and testosterone levels in rats (Grewal et al., 1971; Howland, 1975; Campbell et al., 1977). Female hamsters that were deprived of food for 1 or 2 oestrous cycles or restricted to $50 \%$ of normal food intake for 2 oestrous cycles had reduced uterine weights, no ovarian follicular development and a decrease in the percentage of animals ovulating (Printz \& Greenwald, 1970; Howland \& Skinner, 1973a; Morin, 1975).

The role of the pineal gland in mediating short day-induced gonadal regression of rodents is well documented (Reiter, 1981). However, the pineal gland does not transduce the effects of low temperature on the gonads of hamsters; nor does it appear to mediate the effects of food restriction on reproduction of female hamsters or male rats (Reiter, 1968; Sorrentino, Reiter \& Schalch, 1971; Liu \& Frehn, 1973; Morin, 1975). The present experiments assessed the effect of reduced food availability on reproductive function of intact and pinealectomized male hamsters.

* Present address: Department of Physiology \& Biophysics, Dalhousie University, Halifax, Nova Scotia, Canada $\mathrm{B} 3 \mathrm{H} 4 \mathrm{H} 7$. 


\section{Materials and Methods}

Housing conditions. Adult (6-7 months old) male golden hamsters born in the laboratory to stock animals (lak: LVG) derived from Lakeview Hamster Colony (Newfield, N.J.) were maintained from birth in a photoperiod of $14 \mathrm{~h}$ light $/ 24 \mathrm{~h}$ (lights on at $07: 45 \mathrm{~h}$, Pacific Standard Time). They were housed individually in wire-bottomed cages in this $14 \mathrm{~L}: 10 \mathrm{D}$ cycle, except as noted. Access to food (Simonsen rat pellets, maintenance diet) was restricted for some animals as described below; water was available ad libitum. Room temperature was maintained at approximately $23^{\circ} \mathrm{C}$.

Laparotomy and testis measurements. Animals were laparotomized under pentobarbitone sodium anaesthesia $(80 \mathrm{mg} / \mathrm{kg}$ body $\mathrm{wt})$ according to the procedure described by Rusak \& Morin (1976). The maximum length and width of the right testis were measured to the nearest $0.1 \mathrm{~mm}$. A testicular index (TI) was calculated for each hamster (testis length $\times$ testis width/body weight); TI and testis width are correlated with testis weight, which reflects spermatogenesis and testosterone production (Desjardins, Ewing \& Johnson, 1971; Rusak \& Morin, 1976; Turek \& Losee, 1978; Reiter, 1981). Laparotomies were performed on all animals before the start of the experimental procedures and groups were balanced for mean body weight and TI values (Tables 1 and 2).

Pinealectomy. At least 1 month before the start of the experimental procedures, 15 animals were both laparotomized and pinealectomized using the method of Hoffman \& Reiter (1965). At the end of the experiment 7 pinealectomized animals with redeveloped gonads were chosen at random to be placed in a $10 \mathrm{~L}: 14 \mathrm{D}$ photoperiod to verify the pinealectomy procedure functionally; removal of the pineal gland is known to prevent gonadal regression in short photoperiods (Reiter, 1981).

Experimental procedure. In April, beginning on experimental Day 1, the body weights of intact and pinealectomized animals were reduced by initially restricting food availability to a $2-3 \mathrm{~h}$ period daily $(08: 00-11: 00 \mathrm{~h})$ for 5 days. Thereafter, $6-8 \mathrm{~g}$ of food were provided daily to maintain hamsters at approximately $70-75 \%$ of their former individual body weights. Body weight and food intake were measured at the time of daily food replenishment $(08: 00 \mathrm{~h})$. Hamsters were maintained at the reduced weight until testicular regression occurred; ad-libitum feeding was then reinstated. All animals were laparotomized on Day 77 to measure testicular size; laparotomies were repeated on Days 113 and 160 for those animals that had not shown testicular regression earlier. Hamsters with a TI $<1 \cdot 1$ were considered to exhibit 'complete' testicular regression since a TI of 1.0 or lower is characteristic of hamsters that have undergone short day-induced gonadal regression (Rusak \& Morin, 1976) and have histologically atrophic testes (Reiter, 1981). Those hamsters that manifested testicular regression were fed ad libitum for 73-85 days and then laparotomized to measure the effects of re-feeding on testis size. Hamsters that did not exhibit testicular regression in response to underfeeding by Day 160 were given free access to food after laparotomy. After ad-libitum feeding for 87 days, the response of the reproductive systems of these animals to light deprivation was assessed by laparotomy before, and 74 days after, blinding by bilateral orbital enucleation. Ten animals given free access to food throughout the study served as a control group.

Statistical analysis. Statistical comparisons of body weights and testis dimensions were computed using one-way analyses of variance (ANOVA) on the data derived from laparotomies on Days 77 and 160 and after re-feeding. A significant result was followed by two group comparisons (intact-underfed versus control, pinealectomized-underfed versus control), using $t$ tests. Only data from animals that completed the experiment were analysed.

\section{Results}

Body weights. After 77 days of food restriction, the body weights of intact and pinealectomized animals were $76 \%$ and $74 \%$ respectively of initial body weight values and were significantly reduced compared to controls (Table 1). There were no differences in mean \pm s.e.m. body weights between animals with incomplete testicular regression and animals with complete gonadal atrophy 
in either food-restricted group (intact: $94.0 \pm 3.5$ and $94.8 \pm 1.7 \mathrm{~g}$; pinealectomized : $93.0 \pm 6.6$ and $96.8 \pm 4.3 \mathrm{~g}$ respectively). Underfeeding was continued for animals with incomplete testicular regression; mean body weights of intact and pinealectomized animals were reduced to $69-70 \%$ and $64-69 \%$ of initial values, respectively, by Days 113 and 160 (Table 1).

Table 1. Effects of underfeeding on body weight (g) of hamsters

\begin{tabular}{|c|c|c|c|c|}
\hline \multirow[b]{2}{*}{ Group } & \multicolumn{4}{|c|}{ Days of food restriction } \\
\hline & 0 & 77 & $113 \dagger$ & $160 \dagger$ \\
\hline Intact, underfed & $\begin{array}{c}124 \cdot 5 \pm 2 \cdot 7 \\
(18)\end{array}$ & ${ }_{(18)}^{94 \cdot 2 \pm 2 \cdot 4^{*}}$ & ${ }_{(12)}^{85 \cdot 6 \pm 3 \cdot 1}$ & $87 \cdot 8 \underset{(8)}{ \pm} 2 \cdot 1^{*}$ \\
\hline $\begin{array}{l}\text { Pinealectomized, } \\
\text { underfed }\end{array}$ & $\begin{array}{c}130 \cdot 1 \pm 5 \cdot 1 \\
(15)\end{array}$ & $\begin{array}{c}95 \cdot 8 \pm 3.5^{*} \\
(15)\end{array}$ & $82 \cdot 8 \underset{(4)}{ \pm} 5 \cdot 8$ & $90 \cdot 2 \pm 3.9$ \\
\hline $\begin{array}{l}\text { Control, fed } \\
\text { ad libitum }\end{array}$ & $\begin{array}{c}129 \cdot 4 \pm 2 \cdot 9 \\
(10)\end{array}$ & ${ }_{(10)}^{126 \cdot 7}{ }^{3 \cdot 4}$ & & ${ }_{(10)}^{125 \cdot 6 \pm 3 \cdot 3}$ \\
\hline
\end{tabular}

Values are mean \pm s.e.m. for the no. of animals given in parentheses.

+ Underfeeding was continued only for those animals with incomplete testicular regression ( $T I \geqslant 1 \cdot 1)$. Means for Days 113 and 160 include only values for animals that underwent continued food restriction.

${ }^{*} P<0.001$ compared with control value.

Free access to food for 73-85 days in hamsters with regressed testes restored the body weights to near control levels (Table 3).

Testis dimensions. After 77 days of food restriction, the gonads of intact and pinealectomized animals were significantly smaller than those of control animals $(P<0.001)$, whether calculated in absolute dimensions (testis width) or corrected for body weight (TI; Table 2). Six of 18 intact animals and $11 / 15$ pinealectomized underfed animals had completely regressed gonads (intact: $\mathrm{TI}$ $=0.78 \pm 0.06$, testis width $=6.38 \pm 0.24$; pinealectomized $: \mathrm{TI}=0.71 \pm 0.04$, testis width $=6.11$ $\pm 0.22 \mathrm{~mm}$ ). Animals with incomplete testicular regression were continued on food restriction; by Day 113 the testes of 4 more intact animals were completely regressed $(\mathrm{TI}=0.96 \pm 0.06$, testis width $=7.68 \pm 0.31 \mathrm{~mm}$ ).

Table 2. Effects of underfeeding on testis index (TI) and testis width (TW) of hamsters

\begin{tabular}{|c|c|c|c|c|c|c|c|}
\hline \multirow[b]{3}{*}{ Group } & \multicolumn{7}{|c|}{ Days of food restriction } \\
\hline & \multirow{2}{*}{$\begin{array}{r}0 \\
\text { TI }\end{array}$} & \multicolumn{2}{|c|}{77} & \multicolumn{2}{|c|}{$113 \dagger$} & \multicolumn{2}{|c|}{$160 \dagger$} \\
\hline & & TI & TW & TI & TW & TI & TW \\
\hline $\begin{array}{l}\text { Intact, } \\
\text { underfed }\end{array}$ & $\underbrace{2.0}_{0.05}$ & $\begin{array}{l}1 \cdot 39 \pm \\
0 \cdot 15^{* * *}\end{array}$ & $\begin{array}{l}8 \cdot 69 \pm \\
0.49^{* * *}\end{array}$ & $\begin{array}{c}1.59 \pm \\
0.15\end{array}$ & $\begin{array}{c}9.67 \pm \\
0.46\end{array}$ & $\begin{array}{r}1.84 \pm \\
0.12^{*}\end{array}$ & $\begin{array}{r}10.65 \pm \\
0.48^{* *}\end{array}$ \\
\hline No. & 18 & 18 & 18 & 12 & 12 & 8 & 8 \\
\hline $\begin{array}{l}\text { Pinealec- } \\
\text { tomized } \\
\text { underfed }\end{array}$ & $\begin{array}{r}2.01 \pm \\
0.07\end{array}$ & $\begin{array}{c}0.96 \pm \\
0.12^{\neq * *}\end{array}$ & $\begin{array}{l}6.99 \pm \\
0.48^{* * *}\end{array}$ & $\begin{array}{r}2.09 \pm \\
0.14\end{array}$ & $\underset{0.35}{11.3} \pm$ & $\begin{array}{r}2 \cdot 20 \pm \\
0.14\end{array}$ & $\frac{12 \cdot 1 \pm}{0.71^{*}}$ \\
\hline No. & 15 & 15 & 15 & 4 & 4 & 4 & 4 \\
\hline $\begin{array}{r}\text { Control, fed } \\
\text { ad libitum }\end{array}$ & $\begin{array}{r}1.97 \pm \\
0.06\end{array}$ & $\begin{array}{r}2.22 \pm \\
0.06\end{array}$ & $\begin{array}{c}13.89 \pm \\
0.26\end{array}$ & & & $\begin{array}{r}2 \cdot 11 \pm \\
0.04\end{array}$ & $\begin{array}{c}13.44 \pm \\
0.24\end{array}$ \\
\hline No. & 10 & 10 & 10 & & & 10 & 10 \\
\hline
\end{tabular}

Values are mean \pm s.e.m.

$\dagger$ Underfeeding was continued only for those animals with incomplete testicular regression (TI $\geqslant 1 \cdot 1)$. Means for

Days 113 and 160 include only values for animals that underwent continued food restriction.

Compared with control value: $* P<0.05 ; * * P<0.005 ;^{* * *} P<0.001$. 
While the remaining 8 intact and 4 pinealectomized underfed animals did not show complete testicular regression after 160 days of underfeeding, mean testis width of both groups was significantly smaller than the control values (Table 2). The mean TI of intact underfed animals was also significantly lower than the control mean (Table 2).

Animals with regressed testes given free access to food for 73-85 days exhibited testicular redevelopment; the mean TI and testis width of intact and pinealectomized males did not differ from those of intact control males (Table 3). The functional nature of the pinealectomies was confirmed in 7 animals with redeveloped gonads placed in short days (10L:14D) for 74 days; these animals did not show testicular regression $(\mathrm{TI}=1.83 \pm 0.09$, testes width $=11.97 \pm 0.56 \mathrm{~mm})$.

Table 3. Effects of refeeding on testis dimensions and body weight of hamsters*

\begin{tabular}{lccc}
\hline Group & Body Weight $(\mathrm{g})$ & Testis Index & Testis Width (mm) \\
\hline $\begin{array}{l}\text { Intact, refed } \\
(\mathrm{N}=10)\end{array}$ & $118.5 \pm 4 \cdot 1$ & $1.90 \pm 0.07$ & $12.36 \pm 0.32$ \\
$\begin{array}{l}\text { Pinealectomized, refed } \\
(\mathrm{N}=11)\end{array}$ & $121.3 \pm 6.5$ & $1.94 \pm 0.10$ & $12.71 \pm 0.33$ \\
$\begin{array}{l}\text { Control, fed ad libitum } \\
(\mathrm{N}=10)\end{array}$ & $125.6 \pm 3.3$ & $2.11 \pm 0.04$ & $13.44 \pm 0.24$ \\
\hline
\end{tabular}

Values are mean \pm s.e.m.

* Animals with completely regressed testes (TI < 1.1) were refed for 73-85 days.

Intact animals whose testes did not regress in response to food restriction were given free access to food after 160 days of food restriction; after 87 days of ad-libitum feeding animals were laparotomized (TI $=2.0 \pm 0 \cdot 16$, testis width $=12.67 \pm 0.27 \mathrm{~mm}$ ) and blinded. All animals showed complete gonadal regression 74 days after blinding $(\mathrm{TI}=0.69 \pm 0.07$, testis width $=6.9 \pm$ $0.51 \mathrm{~mm})$.

\section{Discussion}

Food restriction in hamsters for 11-16 weeks decreased body weight to approximately $70-75 \%$ of initial levels. Weight loss was accompanied by substantial testicular regression that was complete in the majority of hamsters. Resumption of ad-libitum feeding in animals with completely regressed testes restored body weights to near control levels and permitted testicular redevelopment. These findings indicate that chronic food restriction can affect reproduction in hamsters. Weight loss during the winter due to changes in food availability may act in concert with short photoperiods to ensure appropriate timing of the hamster seasonal breeding cycle. Adequate food availability during the breeding season may also be necessary to maintain reproductive capacity. Since hamsters maintained indefinitely in short photoperiods exhibit complete spontaneous testicular redevelopment by 22-25 weeks (Turek, Elliott, Alvis \& Menaker, 1975), it cannot be determined to what degree testicular redevelopment in previously underfed hamsters given food $a d$ libitum is attributable to the resumption of unlimited feeding or to spontaneous testicular regeneration.

Not all hamsters exhibited complete testicular regression in response to underfeeding; the testes of these animals regressed, however, when the animals were blinded. Food availability and body weight most probably function as secondary cues to augment the antigonadal effects of short daylengths and low temperatures. Male hamsters exposed to cold may lose $10-40 \%$ of their body weight (Lyman, 1954; Hoffman et al., 1965; Hoffman, 1968); weight loss per se may contribute to the antigonadal effects of low temperatures. Since not all hamsters respond with gonadal regression when exposed to short days or cold temperature (Hoffman et al., 1965; Reiter \& Sorrentino, 1972; Liu \& Frehn, 1973; Reiter, 1973; Zucker, Johnston \& Frost, 1980), reliance on multiple cues to 
terminate reproduction in the fall may increase the probability of complete gonadal involution during the winter.

Food deprivation was at least as effective in producing gonadal regression in pinealectomized as in intact hamsters; these results parallel those of Morin (1975) and Liu \& Frehn (1973) who reported no effects of pinealectomy on underfeeding or cold-induced gonadal atrophy in hamsters. Pinealectomy also did not reverse the antigonadal effects of underfeeeding in blinded rats (Sorrentino et al., 1971).

One antigonadal effect of acute food deprivation is an increase in the sensitivity of the hypothalamic-hypophysial mechanisms regulating gonadotrophin secretion to the negative feedback effects of testosterone. Fasted castrated rats show an inhibition of $\mathrm{LH}$ release at lower levels of testosterone replacement than do control castrates (Howland, 1979; Pirke \& Spyra, 1981). This change in the steroid-dependent hypothalamic mechanism regulating $\mathrm{LH}$ release appears similar to the increase in steroidal negative feedback sensitivity resulting from gonadal regression due to short-day exposure in hamsters (Turek \& Campbell, 1979). However, while exposure to short days results in an attenuation of the castration-induced rise of gonadotrophins in hamsters (Turek \& Campbell, 1979), the castration-induced rise of gonadotrophins in rats is not prevented by acute starvation (Root \& Russ, 1972; Root \& Duckett, 1973; Howland \& Skinner, 1973b; Pirke \& Spyra, 1981).

The occurrence of seasonal breeding cycles in golden hamsters appears to be under the synergistic influence of multiple environmental stimuli (photoperiod, temperature and food availability). Neuroendocrine mechanisms underlying the effects of nutrition and temperature on reproduction differ from those underlying photoperiodic effects. The pineal gland is essential for transducing daylength information but not for mediating the effects of reduced food availability or low temperatures.

I am grateful to I. Zucker and B. Rusak for their helpful comments on the manuscript and to D. Frost and P. Roisman for their technical assistance. This research was supported by Grant HD02982 from the U.S. Public Health Service to I. Zucker.

\section{References}

Campbell, G.A., Kurcz, M., Marshall, S. \& Meites, J. (1977) Effects of starvation in rats on serum levels of follicle stimulating hormone, luteinizing hormone, thyrotropin, growth hormone and prolactin; response to LH-releasing hormone and thyrotropin-releasing hormone. Endocrinology 100, 580-587.

Desjardins, C., Ewing, L.L. \& Johnson, B.H. (1971) Effects of light deprivation upon the spermatogenic and steroidogenic elements of the hamster testis. Endocrinology 89, 791-800.

Frehn, J.L. \& Liu, C.-C. (1970) Effects of temperature, photoperiod and hibernation on the testes of golden hamsters. J. exp. Zool. 174, 317-323.

Gaston, S. \& Menaker, M. (1967) Photoperiodic control of hamster testis. Science, N.Y. 158, 925-928.

Grewal, T., Mickelson, O. \& Hafs, H.D. (1971) Androgen secretion and spermatogenesis in rats following semistarvation. Proc. Soc. exp. Biol. Med. 138, 723-727.

Hoffman, R.A. (1968) Hibernation and effects of low temperature. In The Golden Hamster, It's Biology and Use in Medical Research, pp. 25-39. Eds R. A. Hoffman, P. F. Robinson \& H. Magalhaes. Iowa State Univ. Press, Ames, Iowa.

Hoffman, R.A. \& Reiter, R.J. (1965) Rapid pinealectomy in hamsters and other small rodents. Anat. Rec. 153, 19-22.
Hoffman, R.A., Hester, R.J. \& Towns, C. (1965) Effect of light and temperature on the endocrine system of the golden hamster (Mesocricetus auratus Waterhouse). Comp. Biochem. Physiol. 15, 525-533.

Howland, B.E. (1975) The influence of feed restriction and subsequent re-feeding on gonadotrophin secretion and serum testosterone levels in male rats. $J$. Reprod. Fert. 44, 429-436.

Howland, B.E. (1979) Effect of underfeeding on the inhibition of gonadotrophin secretion by testosterone propionate in rats. J. Reprod. Fert. 55, 335-338.

Howland, B.E. \& Skinner, K.R. (1973a) Effect of starvation on LH levels in male and female hamsters. J. Reprod. Fert. 32, 505-507.

Howland, B.E. \& Skinner, K.R. (1973b) Effect of starvation on gonadotrophin secretion in intact and castrated male rats. Can. J. Physiol. Pharmacol. 51, 759-762.

Kenagy, G.J. \& Bartholomew, G.A. (1981) Effects of day length, temperature and green food on testicular development in a desert pocket mouse Perognathus formosus. Physiol. Zool. 54, 62-73.

Kirkpatrick, R.L. \& Kibbe, D.P. (1971) Nutritive restriction and reproductive characteristics of captive cottontail rabbits. J. Wildl. Mgmt 35, 332-338. 
Liu, C.-C. \& Frehn, J.L. (1973) Failure of pineal removal to prevent some cold-induced testicular changes in golden hamsters. Experientia 29, 1507-1509.

Lyman, C.P. (1954) Activity, food consumption and hoarding in hibernators. J. Mammal. 35, 545-552.

Morin, L.P. (1975) Effects of various feeding regimens and photoperiod or pinealectomy on ovulation in the hamster. Biol. Reprod. 13, 99-103.

Mulinos, M.G. \& Pomerantz, L. (1941) The reproductive organs in malnutrition. Effects of chorionic gonadotropin upon atrophic genitalia of underfed male rats. Endocrinology 29, 267-275.

Pinter, A.J. \& Negus, N.C. (1965) Effects of nutrition and photoperiod on reproductive physiology of Microtus montanus. Am. J. Physiol. 208, 633-638.

Pirke, K.M. \& Spyra, B. (1981) Influence of starvation on testosterone-luteinizing hormone feedback in the rat. Acta endocr., Copenh. 96, 413-421.

Printz, R.H. \& Greenwald, G.S. (1970) Effects of starvation on follicular development in the cyclic hamster. Endocrinology 86, 290-295.

Reiter, R.J. (1968) Changes in the reproductive organs of cold-exposed and light-deprived female hamsters (Mesocricetus auratus). J. Reprod. Fert. 16, 217-222.

Reiter, R.J. (1973) Pineal control of a seasonal reproductive rhythm in male golden hamsters exposed to natural daylight and temperature. Endocrinology 92, 423-430.

Reiter, R.J. (1981) Reproductive effects of the pineal gland and pineal indoles in the Syrian hamster and the albino rat. In The Pineal Gland, Vol. II. Reproductive Effects, pp. 45-81. Ed. R. J. Reiter. CRC Press, Boca Raton, Florida.

Reiter, R.J. \& Sorrentino, S., Jr (1972) Prevention of pineal-mediated reproductive responses in lightdeprived hamsters by partial or total isolation of the medial basal hypothalamus. J. Neuro-Visc. Rel. 32, 355-367.

Root, A.W. \& Duckett, G.E. (1973) In vivo and in vitro effects of synthetic luteinizing hormone-releasing hormone (LH-RH) upon the secretion of luteinizing hormone ( $\mathrm{LH})$ and follicle-stimulating hormone (FSH) in intact and castrated, fed and starved adult male rats. Proc. Soc. exp. Biol. Med. 144, 30-33.

Root, A.W. \& Russ, R.D. (1972) Short-term effects of castration and starvation upon pituitary and serum levels of luteinizing hormone and follicle stimulating hormone in male rats. Acta endocr., Copenh. 70, 665675.

Rusak, B. \& Morin, L.P. (1976) Testicular responses to photoperiod are blocked by lesions of the suprachiasmatic nuclei in golden hamsters. Biol. Reprod. 15, 366-374.

Smith, I.D. (1965) The influence of level of nutrition during winter and spring upon oestrous activity in the ewe. Wld Rev. Anim. Prod. 4, 95-102.

Sorrentino, S., Jr, Reiter, R.J. \& Schalch, D.S. (1971) Interactions of the pineal gland, blinding, and underfeeding on reproductive organ size and radioimmunoassayable growth hormone. Neuroendocrinology $7,105-115$.

Turek, F.W. \& Campbell, C.S. (1979) Photoperiodic regulation of neuroendocrine-gonadal activity. Biol. Reprod. 20, 32-50.

Turek, F.W. \& Losee, S.H. (1978) Melatonin-induced testicular growth in golden hamsters maintained on short days. Biol. Reprod. 18, 299-305.

Turek, F.W., Elliott, J.A., Alvis, J.D. \& Menaker, M. (1975) Effect of prolonged exposure to nonstimulatory photoperiods on the activity of the neuroendocrine-testicular axis of golden hamsters. Biol. Reprod. 13, 475-481.

Watts, C.H.S. (1970) Effect of supplementary food on breeding in woodland rodents. J. Mammal. 51, 169171.

Zucker, I., Johnston, P.G. \& Frost, D. (1980) Comparative, physiological and biochronometric analyses of rodent seasonal reproductive cycles. Prog. Reprod. Biol. 5, 102-133. 